\title{
Association of oral HPV16 infection with periodontal inflammation and the oral microbiome in older women
}

\author{
HIDEO SHIGEISHI $^{1}$, CHENG-YIH SU ${ }^{2}$, YOSHINO KANEYASU ${ }^{1}$, MARI MATSUMURA ${ }^{1}$, MARIKO NAKAMURA ${ }^{1}$, \\ MOMOKO ISHIKAWA $^{1}$, AYUMI SAITO ${ }^{1}$, KOUJI OHTA ${ }^{1}$ and MASARU SUGIYAMA ${ }^{1}$
}

\author{
Departments of ${ }^{1}$ Public Oral Health and ${ }^{2}$ Oral Health Management, Program of Oral Health Sciences, \\ Graduate School of Biomedical and Health Sciences, Hiroshima University, Hiroshima 734-8553, Japan
}

Received October 31, 2019; Accepted January 29, 2020

DOI: $10.3892 / \mathrm{etm} .2020 .9598$

\begin{abstract}
The present preliminary study aimed to investigate the association between oral human papillomavirus type 16 (HPV16) DNA prevalence and periodontal inflammation in older women. The association between oral HPV16 infection and oral health status has not been fully elucidated in older Japanese women. The present study investigated older women aged $\geq 60$ years who visited Hiroshima University Hospital. The present study excluded subjects with clinical factors affecting HPV infection, such as current smoking, oral cancer and pre-malignant lesions, and immunodeficiency. Finally, 46 female patients (mean age, 74.6 years) were analyzed. Quantitative PCR analysis was performed to detect HPV16 DNA in oral rinse samples. A total of 4 participants (8.7\%) were HPV16 DNA positive. There was a significant association between the HPV16 DNA positivity rate and bleeding on probing $(\mathrm{P}=0.03)$. Additionally, Prevotella intermedia positive cases exhibited a significantly higher HPV16 DNA positivity rate than negative cases (33.3 vs 3.8\%). Furthermore, analysis of $16 \mathrm{~S}$ ribosomal RNA in bacterial flora was performed to examine microbiome diversity in participants with $\geq 6 \mathrm{~mm}$ periodontal pockets and bleeding on probing. Importantly, the average percentage of Porphyromonas was significantly higher in HPV16 DNA positive cases compared with in HPV16 DNA negative cases (5.57 vs. 1.44\%). By contrast, the average percentage of Veillonella was significantly lower in HPV16 DNA positive cases than in HPV16 DNA negative cases (2.43 vs. $8.51 \%)$. Prevotella was also lower in HPV16 DNA positive cases than in HPV16 DNA negative cases $(4.0$ vs. $8.23 \%)$. These results indicated that people with both deep periodontal pocket inflammation and oral HPV16
\end{abstract}

Correspondence to: Dr Hideo Shigeishi, Department of Public Oral Health, Program of Oral Health Sciences, Graduate School of Biomedical and Health Sciences, Hiroshima University, 1-2-3 Kasumi, Minami-ku, Hiroshima 734-8553, Japan

E-mail: shige@hiroshima-u.ac.jp

Key words: human papillomavirus 16, microbiome, oral health, periodontitis, older women infection may not have Prevotella- or Veillonella-dominant oral microbiomes, and their microbiomes may exhibit their own distinctive characteristics. In conclusion, the results suggested that oral HPV16 infection may be associated with periodontal inflammation in older Japanese women. Further research is required to clarify the detailed association between oral HPV infection and the oral microbiome.

\section{Introduction}

To date, more than 170 human papillomavirus (HPV) genotypes have been reported, of which HPV16 is the most common type in the oral cavity (1). Our previous meta-analysis revealed that oral HPV infection was significantly associated with current smoking and sexual behavior in healthy individuals, but not with drinking (1). Additionally, men are more susceptible to oral HPV infection than women $(1,2)$, indicating a sex-specific susceptibility to HPV infection in the oral cavity. A higher seroconversion rate in response to genital HPV infection among women may be associated with the low prevalence of HPV16 in the oral cavity (2). A bimodal age peak (i.e., 20-29 years and 60-69 years) for HPV16 infection in the oral cavity exists in Japanese people without oral cancer or oral pre-malignant lesions (3). This finding suggests that a weakened immune system due to aging may be related to oral HPV infection. Thus, it is hypothesized that age-related changes in oral health (e.g., chronic periodontitis and denture use) may be associated with oral HPV infection in older people. However, the relationship between HPV infection and oral health status in older Japanese people remains unknown.

In the present investigation, we examined the HPV16 viral load in the oral cavity and its association with the oral bacterial count (4). An increased number of oral bacteria was significantly associated with a high copy number of HPV16 DNA (4). This result indicates that poor oral hygiene induces viral replication of HPV in the oral cavity. However, the relationship of oral HPV16 infection with oral hygiene has not been fully elucidated among Japanese people.

The oropharynx is a more common site for HPV16 infection than the oral cavity and nasopharynx (5). Viral organisms are thought to become trapped in the tonsillar crypts and then infect basal keratinocytes by invading the epithelium (5). Thus, it is likely that sensitivity to HPV infection is associated 
with the histological features of the local region. In the oral cavity, periodontal pockets are thought to serve as an important reservoir of viral organisms. Additionally, inflammatory periodontal tissue may provide a chance for exposed basal cells to become infected with HPV.

The objective of this study was to conduct a preliminary investigation into the association between HPV16 DNA prevalence and oral health status in older people. Males are significantly associated with a higher prevalence of oral HPV, and this sex difference may be an important factor affecting oral HPV infection rates $(2,3)$. Therefore, we targeted older women to exclude the effect of sex differences on oral HPV infection in this study.

\section{Materials and methods}

Subjects. We targeted 52 women aged $\geq 60$ years who visited the Department of Oral Health of Hiroshima University Hospital from August 2018 to February 2019. We excluded patients with oral cancer or potentially malignant oral disorders (e.g., leukoplakia, erythroplakia or lichen planus) $(n=1)$, those receiving chemotherapy and radiotherapy for cancer $(\mathrm{n}=3)$, those with severe immunodeficiency and auto-immune disease $(n=2)$ and current smokers $(n=0)$ because such clinical factors are thought to be risk factors for oral HPV infection (1). Finally, we analyzed 46 female patients aged $\geq 60$ years (mean age 74.6 years, range 60-94 years). The study design was approved by the Ethics Committee of Hiroshima University (no. E-1022) and all participants signed an informed consent agreement.

Oral rinse sample collection and DNA extraction. An oral rinse sample was collected after subjects rinsed with $10 \mathrm{ml}$ of saline for $15 \mathrm{sec}$. Immediately after collection, all samples were centrifuged at $2,580 \mathrm{xg}$ for $10 \mathrm{~min}$, then the supernatant was decanted and the pellets were stored at $-80^{\circ} \mathrm{C}$ until further processing. DNA was extracted from the oral rinse sample and purified using a PureLink ${ }^{\mathrm{TM}}$ Microbiome DNA Purification Kit (Thermo Fisher Scientific, Inc.).

Oral examination. After collection of the oral rinse sample, an oral examination including a periodontal examination (i.e., assessment of probing depth and bleeding on probing) was performed by an experienced dentist from the Oral Health Department at Hiroshima University Hospital. Probing depth and bleeding on probing was examined at six sites (mesiobuccal, buccal, distobuccal, mesiolingual, lingual and distolingual) on all remaining teeth. The number of remaining teeth and denture use were also recorded. Next, dental plaque accumulation was examined using a plaque disclosing agent. Plaque Control Record scores were recorded by an experienced dental hygienist (6). The intrarater reliability of the dental hygienist was assessed using an intraclass correlation coefficient. A dental hygienist calculated PCR scores of 10 patients two times using intraoral photographs of teeth after use of the plaque disclosing agent. The calculated value of the intraclass correlation coefficient was 0.978 , suggesting that the dental hygienist had excellent reliability, when using previously reported criteria for intraclass correlation coefficient (7).
Quantitation of human cell numbers. Human cell numbers were quantified by our previously reported method (3). Briefly, serial 10 -fold dilutions of the pUC57 vector inserted into the human endogenous retrovirus group 3 member 1 (ERV3-1) genome were made with copy numbers ranging from 100 to 109. DNA levels were quantitated using a CFX connect real-time PCR detection system (Bio-Rad Laboratories) with a reaction mixture containing $1.0 \mu \mathrm{l}$ of DNA, $9.0 \mu \mathrm{l}$ of Thunderbird SYBR qPCR Mix (Toyobo Life Science), and each pair of oligonucleotide primers. Amplifications were performed with initial melting at $95^{\circ} \mathrm{C}$ for $5 \mathrm{~min}$, then 35 cycles of denaturing at $95^{\circ} \mathrm{C}$ for $30 \mathrm{sec}$, annealing at $56^{\circ} \mathrm{C}$ for $30 \mathrm{sec}$, and extension at $72^{\circ} \mathrm{C}$ for $1 \mathrm{~min}$. A standard curve indicating cycle threshold (CT) value versus ERV3-1 copy number was used to estimate the number of human cells in each sample.

HPV16 DNA detection. According to our previously reported method (4), quantitative PCR assays were performed using a CFX Connect real-time PCR detection system (Bio-Rad Laboratories) to detect HPV16DNA in the samples. We prepared DNA samples extracted from approximately 1,000-5,000 human cells from each PCR mixture. The primer sequences for HPV16 E6 were 5'-AAGGGCGTAACCGAAATCGGT-3' (sense) and 5'-GTTTGCAGCTCTGTGCATA-3' (antisense). A positive control containing HPV16 DNA extracted from Caski cells was used for the PCR reactions. Copy numbers above the detection limit in a standard curve for HPV16 DNA were assessed as HPV16 positive. Sequencing for the HPV16 E6 region was performed to confirm the HPV16 DNA sequence of PCR products (140 bp). The BigDye Terminator v3.1 cycle sequencing kit (Thermo Fisher Scientific, Inc.) was used for the sequencing reaction. Amplified DNA fragments were sequenced with an ABI PRISM 310 genetic analyzer (Applied Biosystems; Thermo Fisher Scientific, Inc.).

Detecting periodontal disease-related bacteria by PCR. The bacterial 16S rRNA gene was employed to detect periodontal disease-related bacteria using PCR. One microliter of DNA sample was used for the PCR. PCR products were amplified with GoTaq $^{\circledR}$ Green Master Mix (Promega) and previously reported primers. Amplifications were performed with initial melting at $95^{\circ} \mathrm{C}$ for $2 \mathrm{~min}$, then 35 cycles of denaturing at $95^{\circ} \mathrm{C}$ for $1 \mathrm{~min}$, annealing at $57^{\circ} \mathrm{C}$ for $1 \mathrm{~min}$, and extension at $72^{\circ} \mathrm{C}$ for $1 \mathrm{~min}$. PCR primer sets reported previously are as follows $(8,9)$ : Porphyromonas gingivalis, 5'-AGGCAGCTTGCCATACT GCG-3' (sense) and 5'-ACTGTTAGCAACTACCGATGT-3' (antisense); Tannerella forsythia, 5'-GCGTATGTAACCTGCCC GCA-3' (sense) and 5'-TGCTTCAGTGTCAGTTATACCT-3' (antisense); Treponema denticola, 5'-TAATACCGAATGTGCT CATTTACAT-3' (sense) and 5'-TCAAAGAAGCATTCCCTCTT CTTCTTA-3' (antisense); Prevotella intermedia, 5'-TTTGTT GGGGAGTAAAGCGGG-3' (sense) and 5'-TCAACATCTCTG TATCCTGCGT-3' (antisense); and Fusobacterium nucleatum, 5'-AGGGCATCCTAGAATTATG-3' (sense) and 5'-GGGACA CTGAAACATCTCTGTCTCA-3' (antisense). Primer sequences of all bacterial 16S rRNA were 5'-CGTTAGTAATCGTGGAT CAGAATG-3' (sense) and 5'-TGTGACGGGCGGTGTGTA-3' (antisense). After the PCR reaction, $9 \mu \mathrm{l}$ of PCR product was electrophoresed on $2 \%$ agarose gels with ethidium bromide staining. 


\section{Sequence of HPV16 E6 region}

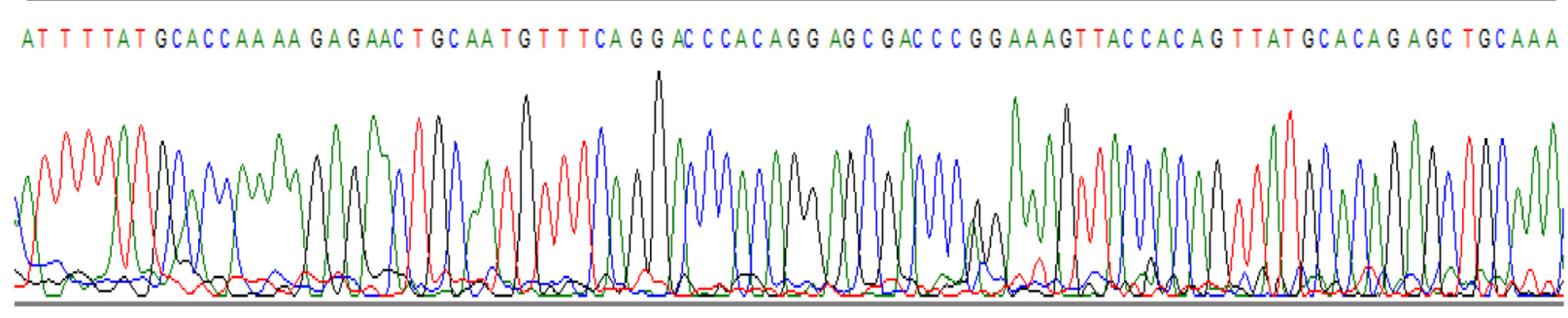

Figure 1. Sequence analysis of the HPV16 E6 region. Sequences for the HPV16 E6 region were investigated using PCR products in HPV16 DNA positive cases. HPV16, human papillomavirus type 16.

$16 S$ rRNA gene sequencing for taxonomic classification of bacteria. According to our previously reported method (4), bacterial flora analysis of the 16S ribosomal RNA gene was performed using DNA obtained from oral rinse samples. Briefly, amplicons were produced, cleaned and sequenced according to the $16 \mathrm{~S}$ Metagenomic Sequencing Library Preparation (Illumina Inc., Part 15044223, Rev. B). After the first and second PCR reaction, the final library was subjected to paired-end sequencing using a MiSeq Reagent Kit v.3 on the Illumina MiSeq platform (Illumina Inc.). After denoising the sequence data, low quality sequences were eliminated and the sequences were clustered into operational taxonomic units (OTUs) at $97 \%$ identity using the CD-HIT-OTU pipeline (10). The Quantitative Insights into Microbial Ecology (QIIME) pipeline was used to analyze the taxonomic classification (11).

Statistical analysis. Statistical analysis was performed using SPSS software, version 24.0 (SPSS Inc.). The $\chi^{2}$ test or Fisher's exact test were used to evaluate significant differences between positive rates of HPV16 DNA and clinical factors. The Student's t-test or Mann-Whitney U test were used to evaluate significant differences in age, remaining teeth, PCR record and average percentage of bacterial genera between HPV16 DNA positive and negative cases. If the Shapiro-Wilk test was statistically significant, the Mann-Whitney U test was used as a non-parametric test. Intrarater reliability was assessed using the intraclass correlation coefficient $(1,1)$. $\mathrm{P}<0.05$ was considered to indicate statistical significance.

\section{Results}

Association between HPV16 DNA positivity and clinical factors. HPV16 DNA positivity was determined in a total of 46 oral rinse samples using quantitative PCR. The CT value of quantitative PCR was above the detection limit in a standard curve in four of the 46 samples $(8.7 \%)$. Additionally, PCR products of the four samples were examined by sequencing for the HPV16 E6 region. The sequence of the HPV16 E6 region was confirmed in the four samples (Fig. 1). Thus, four cases were determined to be HPV16 DNA positive. Table I summarizes the association between HPV16 DNA detected by PCR and clinical factors. There was no significant difference between the HPV16 DNA positivity rate and clinical factors (i.e., sex, age, remaining teeth, denture use, and medical history). Individuals with a medical history of hyperlipidemia
Table I. Association between oral HPV16 DNA and clinical parameters.

\begin{tabular}{|c|c|c|c|}
\hline \multirow[b]{2}{*}{ Clinical factor (n) } & \multicolumn{2}{|c|}{ HPV16 DNA } & \multirow[b]{2}{*}{ P-value } \\
\hline & $(-)$ & $(+)$ & \\
\hline Age, mean $\pm \mathrm{SD}$ & $74.9 \pm 7.4$ & $72.0 \pm 8.6$ & 0.56 \\
\hline Remaining teeth, mean \pm SD & $23.4 \pm 6.5$ & $22.3 \pm 7.9$ & 0.72 \\
\hline Partial denture user, n (\%) & & & 0.35 \\
\hline Non-user (32) & $30(93.8)$ & $2(6.2)$ & \\
\hline User (14) & $12(85.7)$ & $2(14.3)$ & \\
\hline Hypertension, n (\%) & & & 0.65 \\
\hline No (32) & $29(90.6)$ & $3(9.4)$ & \\
\hline Yes (14) & $13(92.9)$ & $1(7.1)$ & \\
\hline Diabetes, n (\%) & & & 0.50 \\
\hline No (39) & $36(92.3)$ & $3(7.7)$ & \\
\hline Yes (7) & $6(85.7)$ & $1(14.3)$ & \\
\hline Hyperlipidemia, n (\%) & & & 0.08 \\
\hline No (40) & $38(95.0)$ & $2(5.0)$ & \\
\hline Yes (6) & $4(66.7)$ & $2(33.3)$ & \\
\hline Stroke, n (\%) & & & 0.91 \\
\hline No $(45)$ & $41(91.1)$ & $4(8.9)$ & \\
\hline Yes (1) & $1(100.0)$ & $0(0.0)$ & \\
\hline Heart disease, $(\%)$ & & & 0.91 \\
\hline No (45) & $41(91.1)$ & $4(8.9)$ & \\
\hline Yes (1) & $1(100.0)$ & $0(0.0)$ & \\
\hline
\end{tabular}

$\mathrm{P}<0.05$ was considered to indicate a statistically significant difference. HPV16, human papillomavirus type 16.

recorded a higher HPV16 DNA positivity rate $(33.3 \%)$ compared with those without $(5.0 \%)$, but the difference was not significant (Table I).

Association between HPVI6 DNA positivity and oral health status. Next, we examined the relationship between HPV16 DNA positivity and dental plaque and periodontal status (Table II). HPV16 DNA positive patients recorded higher Plaque Control Record scores than HPV16 DNA negative patients, but a significant difference was not found. Three of the 14 participants with periodontal pockets $\geq 6 \mathrm{~mm}$ 


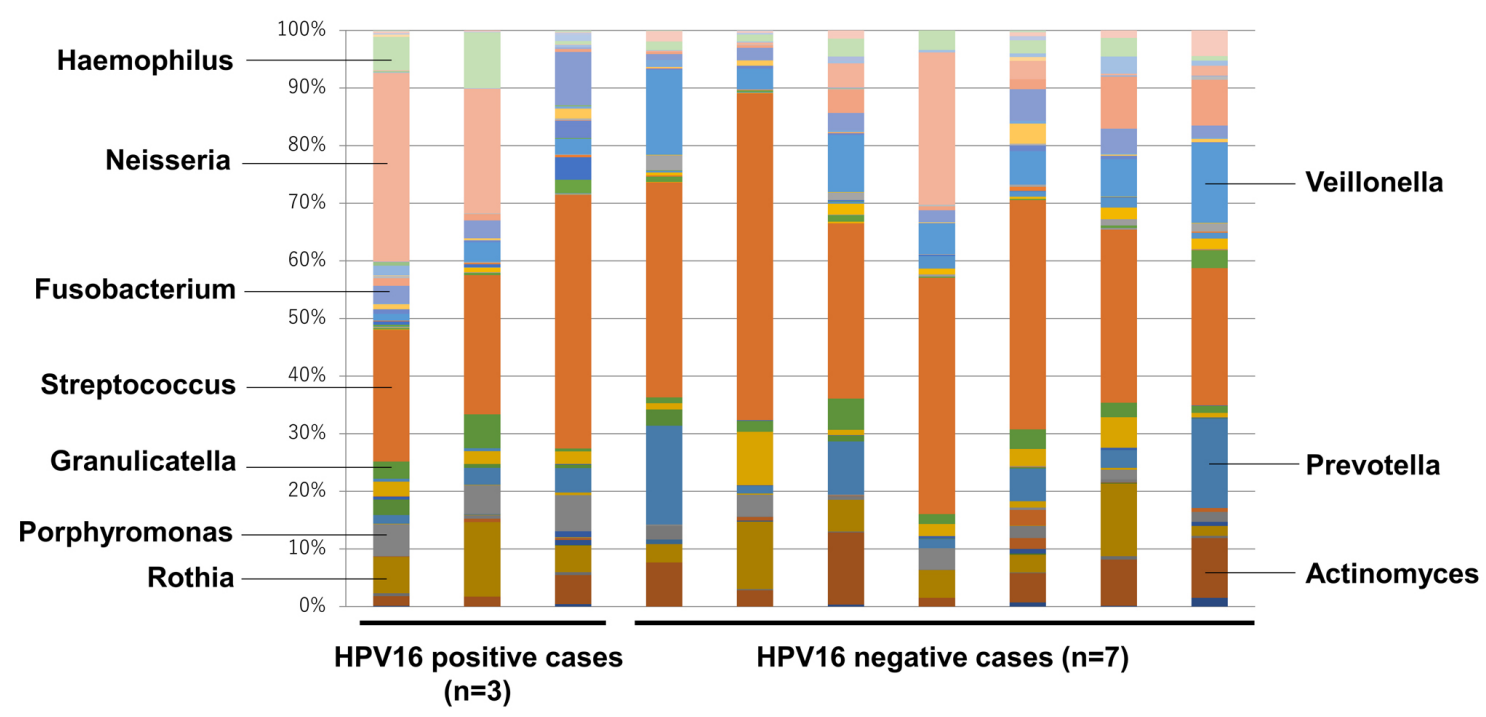

Figure 2. Bacterial flora analysis of the 16S ribosomal RNA gene in participants with periodontitis. Bacterial flora analysis of the 16S ribosomal RNA gene was performed in 10 participants with $\geq 6 \mathrm{~mm}$ periodontal pockets and bleeding on probing. The composition of oral bacteria in HPV16 DNA positive subjects $(\mathrm{n}=3)$ and HPV16 DNA negative subjects $(\mathrm{n}=7)$ is presented. HPV16, human papillomavirus type 16.

Table II. Association between oral HPV16 DNA and oral health status.

\begin{tabular}{llll}
\hline & \multicolumn{2}{c}{ HPV16 DNA } & \\
\cline { 2 - 3 } Factor (n) & \multicolumn{1}{c}{$(-)$} & $(+)$ & P-value \\
\hline $\begin{array}{l}\text { Percentage plaque control } \\
\text { record scores, mean } \pm \text { SD }\end{array}$ & $30.6 \pm 17.9$ & $45.9 \pm 11.1$ & 0.06 \\
Probing depth, n (\%) & & & \\
$\quad<4$ mm (20) & $20(100.0)$ & $0(0.0)$ & \\
$\geq 4$ mm and $<6$ mm (12) & $11(91.7)$ & $1(8.3)$ & \\
$\geq 6$ mm (14) & $11(78.6)$ & $3(21.4)$ & \\
Bleeding on probing, n (\%) & & & 0.03 \\
$\quad$ No (26) & $26(100.0)$ & $0(0.0)$ & \\
Yes (20) & $16(80.0)$ & $4(20.0)$ & \\
\end{tabular}

$\mathrm{P}<0.05$ was considered to indicate a statistically significant difference. HPV16, human papillomavirus type 16.

were HPV16 DNA positive (21.4\%). However, no significant association was found between probing depth and HPV16 DNA positivity. Importantly, all HPV16 DNA positive participants exhibited bleeding on probing. There was a significant association between HPV16 DNA positivity and bleeding on probing $(\mathrm{P}=0.03)$.

Association between HPV16 DNA positivity and periodontal disease-related bacteria. Associations between HPV16 DNA positivity and periodontal disease-related bacteria are summarized in Table III. $T$. forsythia, $P$. intermedia and $F$. nucleatum positive participants exhibited a higher HPV16 DNA positivity rate than $T$. forsythia, $P$. intermedia or $F$. nucleatum negative participants (12.1 vs. $0.0 \%, 33.3$ vs. $3.8 \%$, and 10.8 vs. $0.0 \%$, respectively). Importantly, there was a significant association between HPV16 DNA positivity and P. intermedia $(\mathrm{P}=0.02)$.
Table III. Association between oral HPV16 DNA and periodontal disease-related bacteria.

\begin{tabular}{lccc}
\hline & \multicolumn{2}{c}{ HPV16 DNA } & \\
\cline { 2 - 3 } Clinical factor (n) & $(-)$ & $(+)$ & P-value \\
\hline P. gingivalis, $\mathrm{n}(\%)$ & & & 0.47 \\
Negative (17) & $15(88.2)$ & $2(11.8)$ & \\
Positive (29) & $27(93.1)$ & $2(6.9)$ & \\
T. forsythia, $\mathrm{n}(\%)$ & & & 0.25 \\
Negative (13) & $13(100.0)$ & $0(0.0)$ & \\
Positive (33) & $29(87.9)$ & $4(12.1)$ & \\
T. denticola, $\mathrm{n}(\%)$ & & & 0.63 \\
Negative (25) & $23(92.0)$ & $2(8.0)$ & \\
Positive (21) & $19(90.5)$ & $2(9.5)$ & \\
P. intermedia, $\mathrm{n}(\%)$ & & & \\
Negative (37) & $36(96.2)$ & $1(3.8)$ & \\
Positive (9) & $6(66.7)$ & $3(33.3)$ & \\
F. nucleatum, $\mathrm{n}(\%)$ & & & 0.41 \\
Negative (9) & $9(100.0)$ & $0(0.0)$ & \\
Positive (37) & $33(89.2)$ & $4(10.8)$ & \\
\hline
\end{tabular}

$\mathrm{P}<0.05$ was considered to indicate a statistically significant difference. HPV16, human papillomavirus type 16 .

16S rRNA gene sequence analysis in participants with periodontitis. We performed analysis of $16 \mathrm{~S}$ ribosomal RNA in bacterial flora using oral rinse samples to examine microbiome diversity in 10 participants with $\geq 6 \mathrm{~mm}$ periodontal pockets and bleeding on probing (Fig. 2). It is speculated that HPV16 infection may be associated with particular bacteria in deep periodontal pockets with inflammation. Therefore, we analyzed the association between HPV16 infection and the oral microbiome in patients with periodontal pockets $\geq 6 \mathrm{~mm}$ 
Table IV. Percentage of bacteria genus in participants with periodontal pockets $\geq 6 \mathrm{~mm}$ and bleeding on probing.

\begin{tabular}{|c|c|c|c|}
\hline \multirow[b]{2}{*}{ Genus } & \multicolumn{2}{|c|}{$\begin{array}{c}\text { Average percentage of bacteria } \\
\text { genus, mean } \pm \text { SD }\end{array}$} & \multirow[b]{2}{*}{ P-value } \\
\hline & $\begin{array}{c}\text { HPV16 } \\
\text { DNA (-) } \\
(\mathrm{n}=7)\end{array}$ & $\begin{array}{c}\text { HPV16 } \\
\text { DNA (+) } \\
(\mathrm{n}=3)\end{array}$ & \\
\hline Actinomyces & $6.83 \pm 3.95$ & $2.80 \pm 1.91$ & 0.15 \\
\hline Corynebacterium & $0.21 \pm 0.22$ & $0.33 \pm 0.29$ & 0.22 \\
\hline Rothia & $6.09 \pm 4.33$ & $7.93 \pm 4.38$ & 0.58 \\
\hline Alloscardovia & $0.27 \pm 0.46$ & $0.00 \pm 0.00$ & 0.12 \\
\hline Bifidobacterium & $0.04 \pm 0.08$ & $0.30 \pm 0.06$ & 0.68 \\
\hline Scardovia & $0.24 \pm 0.36$ & $0.3 \pm 0.52$ & 0.52 \\
\hline Atopobium & $1.06 \pm 0.95$ & $0.27 \pm 0.29$ & 0.18 \\
\hline Slackia & $0.01 \pm 0.04$ & $0.07 \pm 0.06$ & 0.27 \\
\hline Bacteroides & $0.00 \pm 0.00$ & $0.33 \pm 0.58$ & 0.52 \\
\hline Paludibacter & $0.50 \pm 1.00$ & $0.00 \pm 0.00$ & 0.38 \\
\hline Porphyromonas & $1.44 \pm 1.67$ & $5.57 \pm 0.60$ & 0.03 \\
\hline Tannerella & $0.23 \pm 0.40$ & $0.23 \pm 0.23$ & 0.52 \\
\hline Prevotella & $8.23 \pm 7.25$ & $4.00 \pm 0.35$ & 0.83 \\
\hline Capnocytophaga & $0.16 \pm 0.17$ & $0.20 \pm 0.26$ & 0.83 \\
\hline SHD-231 & $0.01 \pm 0.04$ & $0.00 \pm 0.00$ & 0.83 \\
\hline Abiotrophia & $0.00 \pm 0.00$ & $0.33 \pm 0.29$ & 0.12 \\
\hline Granulicatella & $2.44 \pm 1.53$ & $3.13 \pm 2.70$ & 0.61 \\
\hline Lactobacillus & $0.03 \pm 0.05$ & $0.00 \pm 0.00$ & 0.52 \\
\hline Streptococcus & $36.99 \pm 10.66$ & $30.27 \pm 11.74$ & 0.40 \\
\hline Butyrivibrio & $0.04 \pm 0.08$ & $0.00 \pm 0.00$ & 0.52 \\
\hline Catonella & $0.24 \pm 0.40$ & $0.07 \pm 0.06$ & 0.27 \\
\hline Moryella & $1.10 \pm 0.80$ & $0.33 \pm 0.40$ & 0.21 \\
\hline Oribacterium & $0.93 \pm 0.78$ & $0.10 \pm 0.00$ & 0.03 \\
\hline Filifactor & $0.07 \pm 0.11$ & $0.87 \pm 1.25$ & 1.0 \\
\hline Peptostreptococcus & $0.09 \pm 0.09$ & $1.67 \pm 1.93$ & 0.02 \\
\hline Dialister & $0.14 \pm 0.26$ & $0.23 \pm 0.15$ & 0.52 \\
\hline Megasphaera & $0.84 \pm 0.97$ & $0.10 \pm 0.10$ & 0.27 \\
\hline Selenomonas & $0.06 \pm 0.05$ & $0.00 \pm 0.00$ & 0.38 \\
\hline Veillonella & $8.51 \pm 4.36$ & $2.43 \pm 1.12$ & 0.01 \\
\hline Mogibacterium & $0.03 \pm 0.05$ & $0.03 \pm 0.06$ & 0.67 \\
\hline Parvimonas & $0.80 \pm 1.23$ & $0.97 \pm 0.70$ & 0.27 \\
\hline Bulleidia & $0.36 \pm 0.40$ & $0.17 \pm 0.21$ & 0.38 \\
\hline Sharpea & $0.00 \pm 0.00$ & $0.07 \pm 0.12$ & 0.52 \\
\hline Fusobacterium & $2.87 \pm 1.54$ & $5.13 \pm 3.52$ & 0.18 \\
\hline Leptotrichia & $3.46 \pm 3.66$ & $0.97 \pm 0.42$ & 0.67 \\
\hline Lautropia & $0.16 \pm 0.22$ & $0.17 \pm 0.21$ & 0.52 \\
\hline Eikenella & $0.03 \pm 0.05$ & $0.13 \pm 0.15$ & 0.67 \\
\hline Kingella & $0.24 \pm 0.40$ & $0.07 \pm 0.06$ & 0.83 \\
\hline Neisseria & $5.20 \pm 9.48$ & $18.13 \pm 16.67$ & 0.67 \\
\hline Desulfovibrio & $0.10 \pm 0.26$ & $0.00 \pm 0.00$ & 0.83 \\
\hline Campylobacter & $0.80 \pm 1.00$ & $0.20 \pm 0.17$ & 0.12 \\
\hline Cardiobacterium & $0.00 \pm 0.00$ & $0.10 \pm 0.17$ & 0.27 \\
\hline Actinobacillus & $0.27 \pm 0.46$ & $0.00 \pm 0.00$ & 0.83 \\
\hline Aggregatibacter & $0.00 \pm 0.00$ & $0.07 \pm 0.06$ & 0.12 \\
\hline Haemophilus & $0.01 \pm 0.04$ & $5.37 \pm 4.57$ & 0.52 \\
\hline Treponema & $0.24 \pm 0.40$ & $0.37 \pm 0.55$ & 0.18 \\
\hline TG5 & $0.13 \pm 0.26$ & $0.20 \pm 0.17$ & 1.0 \\
\hline Mycoplasma & $0.06 \pm 0.11$ & $0.13 \pm 0.15$ & 0.38 \\
\hline
\end{tabular}

$\mathrm{P}<0.05$ was considered to indicate a statistically significant difference. HPV16, human papillomavirus type 16 . and bleeding on probing. We compared the percentage of each bacterial genus between HPV16 DNA positive cases $(n=3)$ and HPV16 DNA negative cases $(n=7)$. At the genus level, a total of 48 genera were found in the two groups, with Streptococcus being most commonly detected in both groups. Importantly, the average percentage of Porphyromonas was significantly higher in HPV16 DNA positive cases than in HPV16 DNA negative cases (5.57 vs. $1.44 \%$ ) (Table IV). In contrast, the average percentage of Veillonella was significantly lower in HPV16 DNA positive cases than in HPV16 DNA negative cases (2.43 vs. $8.51 \%$ ) (Table IV). Additionally, the percentage of Prevotella was lower in HPV16 DNA positive cases than in HPV16 DNA negative cases (4.0 vs. 8.23\%) (Table IV). However, there was no significant difference between the groups. Among the bacterial genera present in small proportions, there was a significant difference in Oribacterium and Peptostreptococcus between the groups (Table IV).

\section{Discussion}

Several studies have investigated the localization of HPV in periodontal tissues. Using in situ hybridization, Hormia et al (12) detected high-risk type HPV DNA in the junctional epithelium of periodontal pockets of patients with periodontal disease. Other studies reported that HPV16 DNA was detected in periodontal tissues and gingival crevicular fluid $(13,14)$. These results indicate that periodontal tissues may serve as important infection sites and reservoirs for HPV. However, HPV16 DNA was not detected in the gingival tissues obtained from Brazilian patients with periodontal disease using quantitative PCR (15). Such different results may be attributed to differences in the sample type, detection method, and clinical factors (i.e., age, sex, race and locality).

Histologic evaluation using in situ hybridization is a reliable method to detect HPV DNA (12). Oral mucosa scraping is a useful method for collection of a sufficient number of human cells (16). In this study, we chose sample collection via oral rinses due to the non-invasive nature of this method. Oral rinse samples contain a mix of human cells, saliva, and microorganisms. Syrjänen (16) reported that oral rinse samples contain more bacteria and fewer human cells, compared with samples obtained from mucosal scrapings. Thus, the large number of bacteria may affect the quality of DNA used for PCR analysis in oral rinse samples (16). Therefore, to minimize the effect of bacteria on PCR analysis results, oral rinse samples should be stored at $-80^{\circ} \mathrm{C}$ immediately after collection to prevent bacteria growth.

Recent research has found a significant association between oral health status and oral HPV infection in adults $(17,18)$. Both periodontal pockets $\geq 6 \mathrm{~mm}$ and clinical attachment loss $\geq 7 \mathrm{~mm}$ were identified as significant risk factors for oral HPV infection in Hispanic people (17). Dental plaque and gingival bleeding were both significant risk factors for high-risk type HPV infection in people aged 18-50 years without oral cancer and a history of HPV vaccination (18). However, there was no significant association between oral HPV16 DNA positivity and oral health status (i.e., dental plaque, calculus and periodontitis) in people aged $18-90$ years without a history of cancer or any systemic disease (19). The National Health and Nutrition Examination Survey data in the USA found 
that there was no significant relationship between oral HPV infection and periodontal disease after adjusting for the participants' clinical parameters (i.e., race, sex, age, smoking, drinking, sexual behavior and education) (20). In this pilot study, we found there was a significant relationship between bleeding on probing (an important sign of tissue inflammation) and HPV16 DNA positivity in older non-smoking people without oral cancer or immunosuppressive conditions. One limitation of our study is the small number of participants; however, our findings suggests that deep periodontal pockets plus periodontal inflammation may be importantly associated with HPV16 infection in periodontal tissues. While it is still controversial whether deep inflammatory periodontal pockets are a risk factor for HPV, it is significant that periodontal tissue may act as a reservoir of HPV in the oral cavity. In accordance with the previous reports by Cutress et al (21), severe periodontitis was defined as the presence of a pocket depth $\geq 6 \mathrm{~mm}$. In addition, de Souza et al (22) reported that bleeding upon probing was significantly correlated with local gingival tissue inflammation (i.e., number of inflammatory cells per area). Bleeding upon probing was considered a vital indicator of periodontal tissue inflammation due to the presence of periodontal pathogens. Importantly, alveolar bone loss can also be used to evaluate the severity of periodontitis. However, we did not examine the severity of alveolar bone loss in this study. Therefore, we presume that our method did not precisely assess the degree of periodontitis (i.e., mild, moderate or severe).

Increased HPV16 E6 viral copy numbers in the oral cavity were associated with an increased number of bacteria, suggesting that oral hygiene status may be involved in viral DNA replication (4). Additionally, $16 \mathrm{~S}$ ribosomal RNA sequences analysis displayed a trend toward oral microbiome differences between people with a high HPV16 viral load and those with a low HPV16 viral load (4). For example, a higher percentage of an anaerobic bacterial genus was found in people with a high HPV16 viral load. In this study, the positive rate of $P$. intermedia was significantly higher in the HPV16 positive group than in the HPV16 negative group. Thus, the presence of such pathogenic bacteria may play a significant role in HPV infection in the oral cavity. Salivary microbiomes with larger proportions of Prevotella and Veillonella genera were associated with periodontitis in Japanese adults (23). This observation suggests that Prevotella and Veillonella play a vital role in the development of periodontitis in Japanese people. In addition, Neisseria and Haemophilus genera were present in much higher proportions in the microbiota of Korean people than in those of Japanese people (23), indicating that there are geographical differences in the oral microbiomes of the two countries. In the analysis of the vaginal microbiome, diversity of vaginal microbiota was strongly associated with HPV infection (24). There was also a significant relationship between high-risk type HPV infection and the Prevotella genus in the vagina of HIV-negative participants (25). These results indicate that changes in the composition of the bacterial microbiome (i.e., increased anaerobic bacteria) play a vital role in vaginal HPV infection. The Prevotella genus may be associated with HPV infection in the vagina.

Several studies have found a significant association between the oral herpes virus (e.g., cytomegalovirus, Epstein-Barr virus, and herpes simplex virus type 1) and periodontal disease $(14,26,27)$. Patients with advanced periodontitis showed positivity for the oral herpes virus as well as HPV in the gingival crevicular fluid (14). Periodontal tissues may be a vital reservoir for viral organisms in the oral cavity. Furthermore, oral herpes virus may impair the balance between the host and the periodontal microbiome by increasing local inflammatory cytokines and suppressing the host immune response $(26,27)$. It is likely that oral viral infection is related to the severity of periodontitis as a result of induction of local inflammatory cytokines in the periodontal tissue. However, it remains unknown whether HPV plays as significant a role as other oral viruses as an inducer of periodontal inflammation. The characteristic oral microbiome may play a role in favor of persistent HPV infection. The healthy microbiome is thought to help maintain a normal immune system to prevent viral infection of the host cells and progression of disease (28). Since HPV16 infection is considered to be a risk factor for the development of oral cavity cancer (29), it is vital to clarify the relationship between HPV16 infection and the oral microbiome. Takeshita et al (30) reported that Prevotella- and Veillonella-dominant oral microbiomes were associated with the active phase of periodontitis (i.e., bleeding on probing) among Japanese people. However, Neisseria-, Haemophilus-, Aggregatibacter- and Porphyromonas-dominant oral microbiomes were related to a healthy periodontium (30). In this study, the Prevotella and Veillonella genera were more prevalent in patients with $\geq 6 \mathrm{~mm}$ periodontal pockets and bleeding on probing without HPV16 infection than in those with HPV16 infection. Interestingly, the Porphyromonas genus was significantly more prevalent in patients with deep periodontal pockets and bleeding on probing with HPV16 infection than in those without HPV16 infection. These results indicate that people with both deep periodontal pocket inflammation and oral HPV16 infection may not have a Prevotella- or Veillonella-dominant oral microbiome and may exhibit different features in their oral microbiomes. However, it remains unknown which particular bacterial species or composition of microbiome is more importantly linked to the prevalence of oral HPV16 infection. Thus, further research is required to clarify significant associations between oral bacteria and oral HPV infection at the genus and species levels.

In conclusion, Oral HPV16 infection may be associated with periodontal inflammation in older Japanese women. However, how HPV localizes in periodontal tissues remains unknown. Accordingly, further research will be necessary to clarify the association between oral HPV infection in the periodontal tissue and periodontal inflammation.

\section{Acknowledgements}

Not applicable.

\section{Funding}

The present study was supported by a Grant-in-aid for Scientific Research (C) (grant no. 15K11290) from the Ministry of Education, Culture, Sports and Technology of Japan.

\section{Availability of data and materials}

All data generated or analyzed during this study are included in this published article. 


\section{Authors' contributions}

HS designed the study, performed experiments, analyzed and interpreted the data and wrote the paper. CYS performed experiments, and analyzed and interpreted the data. YK, MM, MN, MI and AS performed experiments. KO and MS discussed and interpreted the data and aided in writing the paper. All authors read and approved the final manuscript.

\section{Ethics approval and consent to participate}

The study design was approved by the Ethics Committee of Hiroshima University (approval no. E-1022) and all participants signed an informed consent agreement.

\section{Patient consent for publication}

Not applicable.

\section{Competing interests}

The authors declare that they have no competing interests.

\section{References}

1. Shigeishi H and Sugiyama M: Risk factors for oral human papillomavirus infection in healthy individuals: A systematic review and meta-analysis. J Clin Med Res 8: 721-729, 2016.

2. Gillison ML, Broutian T, Pickard RK, Tong ZY, Xiao W, Kahle L, Graubard BI and Chaturvedi AK: Prevalence of oral HPV infection in the United States, 2009-2010. JAMA 307: 693-703, 2012.

3. Shigeishi H, Sugiyama M, Ohta K, Rahman MZ and Takechi M: Higher prevalence and gene amplification of HPV16 in oropharynx as compared to oral cavity. J Appl Oral Sci 24 397-403, 2016.

4. Shigeishi H, Sugiyama M, Ohta K, Yokoyama S, Sakuma M, Murozumi $\mathrm{H}$, Kato $\mathrm{H}$ and Takechi M: High HPV16 E6 viral load in the oral cavity is associated with an increased number of bacteria: A preliminary study. Biomed Rep 8: 59-64, 2018.

5. Faraji F, Zaidi M, Fakhry C and Gaykalova DA: Molecular mechanisms of human papillomavirus-related carcinogenesis in head and neck cancer. Microbes Infect 19: 464-475, 2017.

6. O'Leary TJ, Drake RB and Naylor JE: The plaque control record. J Periodontol 43: 38, 1972.

7. Coppieters M, Stappaerts K, Janssens K and Jull G: Reliability of detecting 'onset of pain' and 'submaximal pain' during neural provocation testing of the upper quadrant. Physiother Res Int 7: 146-156, 2002.

8. Yasukawa T, Ohmori M and Sato S: The relationship between physiologic halitosis and periodontopathic bacteria of the tongue and gingival sulcus. Odontology 98: 44-51, 2010.

9. Yoshida A, Suzuki N, Nakano Y, Oho T, Kawada M and Koga T: Development of a 5' fluorogenic nuclease-based real-time PCR assay for quantitative detection of Actinobacillus actinomycetemcomitans and Porphyromonas gingivalis. J Clin Microbiol 41: 863-866, 2003.

10. Hamada R, Suehiro J, Nakano M, Kikutani T and Konishi K: Development of rapid oral bacteria detection apparatus based on dielectrophoretic impedance measurement method. IET Nanobiotechnol 5: 25-31, 2011.

11. Li W, Fu L, Niu B, Wu S and Wooley J: Ultrafast clustering algorithms for metagenomic sequence analysis. Brief Bioinform 13: 656-668, 2012.
12. Hormia M, Willberg J, Ruokonen $\mathrm{H}$ and Syrjänen S: Marginal periodontium as a potential reservoir of human papillomavirus in oral mucosa. J Periodontol 76: 358-363, 2005.

13. Madinier I, Doglio A, Cagnon L, Lefèbvre JC and Monteil RA: Southern blot detection of human papillomaviruses (HPVs) DNA sequences in gingival tissues. J Periodontol 63: 667-673, 1992.

14. Parra B and Slots J: Detection of human viruses in periodontal pockets using polymerase chain reaction. Oral Microbiol Immunol 11: 289-293, 1996.

15. Horewicz VV, Feres M, Rapp GE, Yasuda V and Cury PR: Human papillomavirus-16 prevalence in gingival tissue and its association with periodontal destruction: A case-control study. J Periodontol 81: 562-568, 2010.

16. Syrjänen S: Oral manifestations of human papillomavirus infections. Eur J Oral Sci 126 (Suppl 1): 49-66, 2018.

17. Ortiz AP, González D, Vivaldi-Oliver J, Castañeda M, Rivera V, Díaz E, Centeno H, Muñoz C, Palefsky J, Joshipura K, et al: Periodontitis and oral human papillomavirus infection among Hispanic adults. Papillomavirus Res 5: 128-133, 2018.

18. Dalla Torre D, Burtscher D, Sölder E, Rasse M and Puelacher W: The correlation between the quality of oral hygiene and oral HPV infection in adults: A prospective cross-sectional study. Clin Oral Investig 23: 179-185, 2019.

19. Sun CX, Bennett N, Tran P, Tang KD, Lim Y, Frazer I, Samaranayake L and Punyadeera C: A pilot study into the association between oral health status and human papillomavirus-16 infection. Diagnostics (Basel) 7: E11, 2017.

20. Wiener RC, Sambamoorthi U and Jurevic RJ: Association of periodontitis and human papillomavirus in oral rinse specimens: Results from the National Health and Nutrition Survey 2009-2012. J Am Dent Assoc 146: 382-389, 2015.

21. Cutress TW, Ainamo J and Sardo-Infirri J: The community periodontal index of treatment needs (CPITN) procedure for population groups and individuals. Int Dent J 37: 222-233, 1987.

22. de Souza PH, de Toledo BE, Rapp GE, Zuza EP, Neto CB and Mendes AJ: Reliability of bleeding and non-bleeding on probing to gingival histological features. J Int Acad Periodontol 5: 71-76, 2003.

23. Takeshita T, Matsuo K, Furuta M, Shibata Y, Fukami K, Shimazaki Y, Akifusa S, Han DH, Kim HD, Yokoyama T, et al: Distinct composition of the oral indigenous microbiota in South Korean and Japanese adults. Sci Rep 4: 6990, 2014.

24. Lee JE, Lee S, Lee H, Song YM, Lee K, Han MJ, Sung J and Ko G: Association of the vaginal microbiota with human papillomavirus infection in a Korean twin cohort. PLoS One 8: e63514, 2013.

25. Dareng EO, Ma B, Famooto AO, Adebamowo SN, Offiong RA, Olaniyan O, Dakum PS, Wheeler CM, Fadrosh D, Yang H, et al: Prevalent high-risk HPV infection and vaginal microbiota in Nigerian women. Epidemiol Infect 144: 123-137, 2016.

26. Gao Z, Lv J and Wang M: Epstein-Barr virus is associated with periodontal diseases: A meta-analysis based on 21 case-control studies. Medicine (Baltimore) 96: e5980, 2017.

27. Rodrigues PM, Teixeira AL, Kustner EC and Medeiros R: Are herpes virus associated to aggressive periodontitis? A review of literature. J Oral Maxillofac Pathol 19: 348-355, 2015.

28. Vyshenska D, Lam KC, Shulzhenko N and Morgun A: Interplay between viruses and bacterial microbiota in cancer development. Semin Immunol 32: 14-24, 2017.

29. Sugiyama M, Bhawal UK, Dohmen T, Ono S, Miyauchi M and Ishikawa T: Detection of human papillomavirus-16 and HPV-18 DNA in normal, dysplastic, and malignant oral epithelium. Oral Surg Oral Med Oral Pathol Oral Radiol Endod 95: 594-600, 2003.

30. Takeshita T, Nakano Y, Kumagai T, Yasui M, Kamio N, Shibata Y, Shiota S and Yamashita Y: The ecological proportion of indigenous bacterial populations in saliva is correlated with oral health status. ISME J 3: 65-78, 2009. 